Research Journal of Applied Sciences 13 (4): 252-257, 2018

ISSN: $1815-932 \mathrm{X}$

(C) Medwell Journals, 2018

\title{
Neural Network for Maritime Weather Prediction
}

\author{
Wimala L. Dhanistha, Herman Pratikno and Silvianita \\ Department of Ocean Engineering, Institute Technology of Sepuluh Nopember, Surabaya, Indonesia
}

\begin{abstract}
Indonesia known as an archipelago where sea transport is transport is dependable by for shipping Inter Island. The height of waves is one of the causes of accidents at sea transportation for that this research will be carried out the prediction of a wave height to minimalise of the accident in sea transportation. Neural network is one of algorithm intelligent for nonlinear advantage predictions which having blackbox can studying the relations between input and output system. Neural network is very suitable as prediktor the waves. The prediction results show that the neural network has small's RMSE.
\end{abstract}

Key words: Neural network, wind speed, wave height, RMSE, maritime, weather

\section{INTRODUCTION}

Neural Network (NN) is one of an algorithm an Artifical Intelligence (AI) that imitates the concept of nerve network system on the human body (Agrawal and Deo, 2004). Neural network is structures in Mathematics with an element the process or nodes that are easy (Sugianto, 2012), neural network is the method efficient to relations complex input-output (Jain and Deo, 2008). Another argument said that the network artificial neural involves the information distribution parallel and able to process nonlinear systems well (Paras et al., 2007). The height of waves is a system that complex and nonlinear (Ainsworth et al., 2011), so as to predict the height of waves match using artificial neural network. Research previous studies algorithm artificial neural network to predict rainfall (rf) and moisture (rh) using data temperature minimum-maximum, rainfall and moisture (Paras et al., 2007), algorithm artificial neural network can predict is better than algorithm nlarx (Hermawan, 2006), a prediction wave height use the neural network and compare it with the regression methods (Gunaydin, 2008), a prediction the wave and wind speed with 3 varians input (Paplinska-Swerpel and Paszke, 2006) and by prediction wave height to the interval 12 and $24 \mathrm{~h}, 5$ and 10 days (Makarynskyy et al., 2004).

Waves is one of the important to cruise (Akhir and Mera, 2011). Waves can be profitable and disadvantages. A wave profitable can help ships to sail while a wave harm may be sink the ship, so, wave high is an important in sea transport (Anonymous, 2012). Wave height is high average of $1 / 3$ the highest and used as a guide cruise. The term is starting from World War 2 (Walter Munk) use the waves to declare high estimation waves

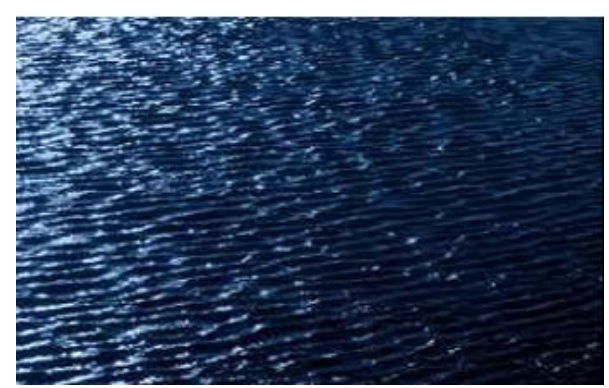

Fig. 1: Ripples (Londhe et al., 2016)

(Aisjah, 2012). Meteorology, climatology and Geophysics (BMKG) served as an observer weather weather predict in a conventional (statistics and dynamic). Previous studies predict the waves on the Java sea using fuzzy logic and produce the accuracy of $74.82 \%$, the accuracy of improved one next year to $81.84 \%$ (Aisjah and Arifin, 2011). With reference to research-previous studies, hence, this research will to optimize syaaf replicas network, so, it can predict the height of waves, so can produce that small error.

Waves: Waves are closely to sea transport. The fluid dynamic is that has distinctive patterns that can be formulated mathematically considering rules and a law. Waves is a major factor in the best layout port, the cruise and building planning coast (Londhe et al., 2016). One of the causes of the waves is wind.

Which the wind blows out of the water will move their energy on water (Londhe et al., 2016). Which the wind blows to constantly would cause for ripple shown in Fig. 1 and will continue to evolve into new waves. The bigger wind speed the prevailing but the larger the waves

Corresponding Author: Wimala L. Dhanistha, Ocean Engineering, Institute Technology of Sepuluh Nopember, Surabaya Indonesia 
formed (Makarynskyy, 2012). A great speed (storm) occurring above sea level power to raise the water fluctuations great sea (Bhattacharya et al., 2003).

Wave height : Wave height is the variable that influence the feasibility shipping and being affected by elevation a high wave. $H_{1 / 3}$ on Eq. 1 is plain flattened $33.3 \%$ waves the highest of recording waves. $\mathrm{H}_{1 / 3}$ is high waves used as guidance shipping and called also waves significant hs. Used waves highest because waves low not much affect shipping 2. The height of waves significant is the variable that influence the feasibility a voyage (Etemad-Shahidi et al., 2009):

$$
\mathrm{H}_{3}=\frac{\mathrm{N}}{3} \sum_{\mathrm{i}=1}^{\mathrm{N} / 3} \mathrm{H}_{\mathrm{i}}
$$

Criteria high waves that affects shipping (Hakim, 2010) is:

- $\quad 1.25-2.0 \mathrm{~m}$ : dangerous to fishing boats

- $\quad 2.0-3.0 \mathrm{~m}$ : dangerous to fishing boats and a barge

- $3.0-4.0 \mathrm{~m}$ : dangerous to fishing boat, a barge and ferry

- >4.0: dangerous to all ships

Neural network: Neural network is an artifical intelligence algorithms that imitates the concept of neural network system in human body, to a node, node that deals between of one by another (Mandal, 2010). The node connected through the links which is called by weight. Neural tissue network is distributed in parallel (Gunaydin, 2008). The basic shape there are neurons in Fig. 2 where the input is the input that will be used for training and validation, weight or weights burden that is always changing every given input as learning, processing unit is a place of the process of the introduction of the occurrence of objects based on the weighting given and output is output of neural network (Gunaydin, 2008). Excess method neural network (Makarynskyy et al., 2004):

- Can be used to forecasting nonlinear systems

- Easy output mapping system without knowing process that occurred (black-box )

- Have the ability to learn a process based on data provided training (Triatmodjo, 1999)

- Represents received information during the training (Triatmodjo, 1999)

Well be a model artificial neural network determined by Triatmodjo (1999):

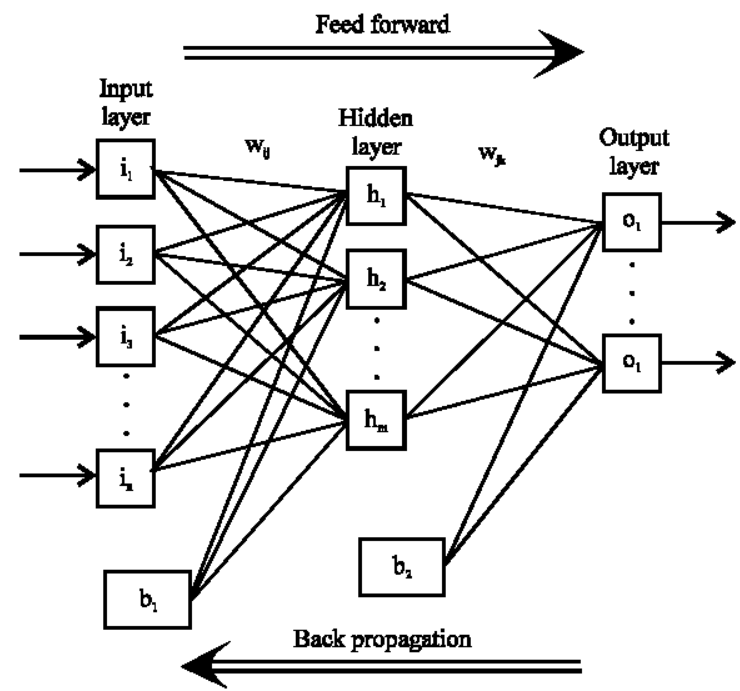

Fig. 2: Basic form neuron (Gunaydin, 2008)

- Architecture network, it was a pattern of architecture determine between neurons

- Method of learning, the methods used to determine and change weights

- Activation function (Deo and Naidu, 1998)

- Selection input (Paplinska-Swerpel and Paszke, 2006)

Performance network: Performance produced by artificial neural network will be evaluated using Root Mean Square Error (RMSE) is an indicator of average error on analysis (Hashim et al., 2016). The less RMSE produced, the more valid value the model (Gunaydin, 2008):

$$
\text { RMSE }=\sqrt{\frac{\sum_{\mathrm{i}=1}^{\mathrm{N}}\left(\mathrm{y}_{\mathrm{i}}-\mathrm{x}_{\mathrm{i}}\right)^{2}}{\mathrm{~N}}}
$$

Where:

$\mathrm{N}=$ Data

$\mathrm{x}_{\mathrm{i}}=$ Measurement

$\mathrm{y}_{\mathrm{i}}=$ Prediction

Data acquisition: Some research mention that the height of waves affected by wind speed and elevation previous waves (Paplinska-Swerpel and Paszke, 2006; Mandal, 2010; Etemad-Shahidi et al., 2009; Peres et al., 2015) this was evidenced by the Small Square Root Mean Error (RMSE) resulting. In a literature review has also mentioned that the height of waves affected by wind speed (Makarynskyy et al., 2004; Srivastava, 1964; Hashim et al., 2016). Then to research this time, data taken is the data on wind speed (vw) and the wave height (hs) in 2006-2010 and 2013. Data retrieval wind speed and altitude waves carried on three points, first on longitude: 112.747800 E latitude: 6.874824 S (Surabaya point A), both 
in longitude: $113.908800 \mathrm{E}$ latitude: $4.648136 \mathrm{~S}$ (the Java sea) point $B$ and third to longitude: $114.484300 \mathrm{E}$ latitude: 3.540425 $\mathrm{S}$ (Banjarmasin point $\mathrm{C}$ ) as in a Fig. 3.

\section{DATA ANALYSIS}

The data performed on research is the wind speed (vw) and altitudes waves (hs) year 2006 until 2011.

Wind: Wind on this study the tides caused by the wind. The data used was data wind speed and the height of the year 2006 until 2011. Used data wind speed the altitude waves influenced by wind speed the prevailing. The less

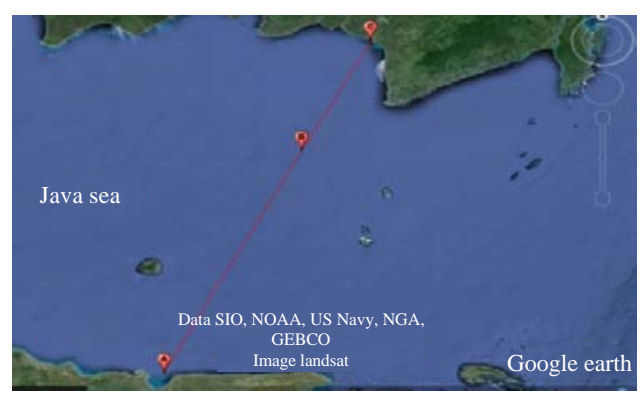

Fig. 3: Location data acquisition wind speed the prevailing, so, the lower the waves happened. But the larger wind speed the prevailing, the higher the level (Paplinska-Swerpel and Paszke, 2006). Figure 4 is a wind speeds are occurred in 2006 until 2011 about 46.016 data wind speed.

Can be seen on a chart that side of wave patterns up and down as many as 5 times because wind speed was taken for 5 years. Where in indonesia is only are 2 seasons that is the rain season and dry season. During the rainy season, wind speed higher than the dry season. So, formed pattern up and down (waves) for five the period. Flattened wind speed per year there are in Table 1. We can pull out from Table 1 until 3 that wind speed every year the highest average happened between december until January or on rainy season.

Wave height : In addition, to the velocity wind, the waves height is also influenced by the height of waves itself at an earlier time. So that, this research need data the height of waves in 2006-2011 as many as 46.016 data the height of waves. Figure 5 is a chart the height of waves. There are three the collection locations data the height of waves on these graphs it first on longitude: $112.747800 \mathrm{E}$ latitude: $6.874824 \mathrm{~S}$ in Surabaya (point A) a blue color, second in

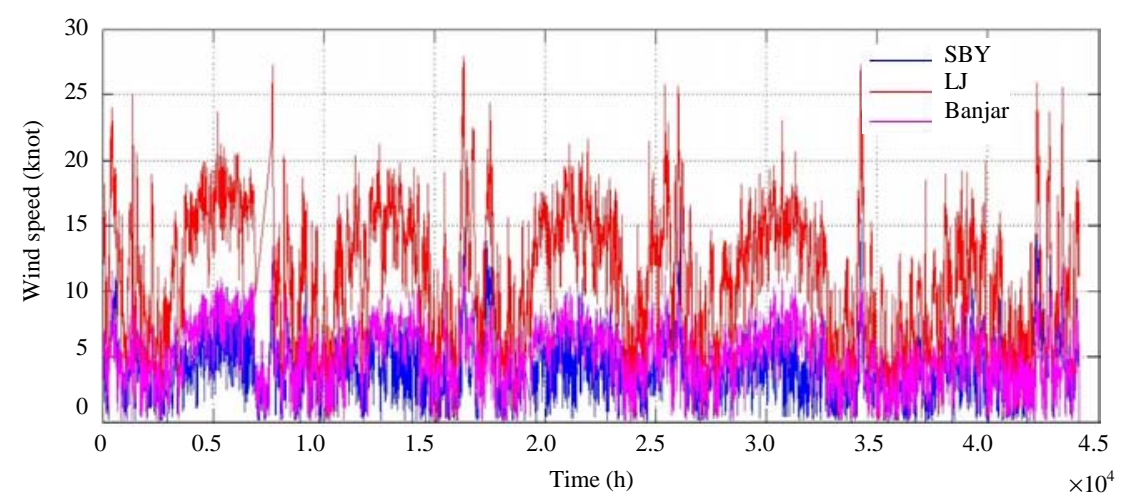

Fig. 4: Wind speed (2006-2001)

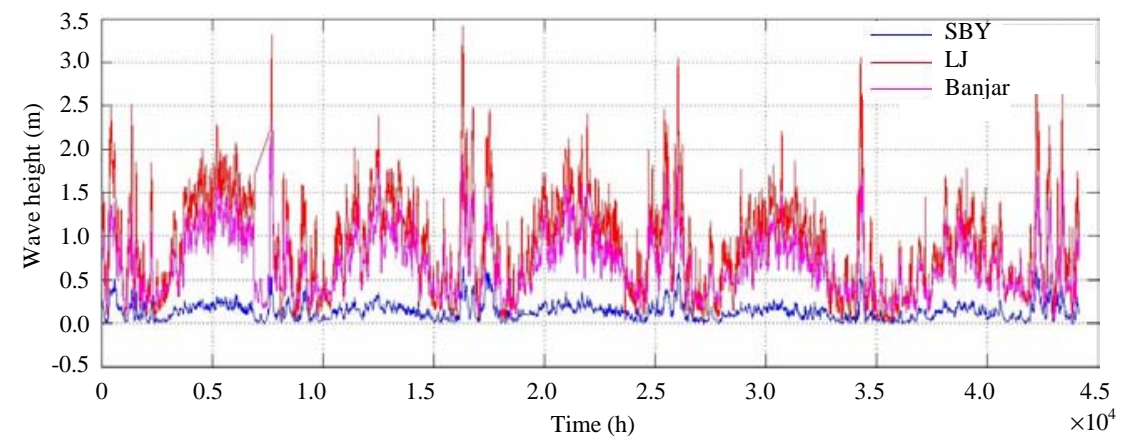

Fig. 5: Wave height 
Res. J. Applied Sci., 13 (4): 252-257, 2018

Table 1: Wind speed point A data's

\begin{tabular}{|c|c|c|c|c|c|c|}
\hline Variables & 2006 & 2007 & 2008 & 2009 & 2010 & 2011 \\
\hline Average & 3.9 & 3.8 & 4.04 & 3.72 & 4.07 & 6.18 \\
\hline Maximum & 11.06 & 14.89 & 13.86 & 16.81 & 10.19 & 14.35 \\
\hline Date & 25 January & 29 December & 9 February & 7 February & 31 December & 12 January \\
\hline \multicolumn{7}{|c|}{ Table 2: Wind speed point B data's } \\
\hline Variables & 2006 & 2007 & 2008 & 2009 & 2010 & 2011 \\
\hline Average & 12.4 & 10.81 & 11.64 & 8.05 & 6.04 & 10.56 \\
\hline Maximum & 25.04 & 27.92 & 24.38 & 22.77 & 15.98 & 25.94 \\
\hline Date & 27 February & 27 December & 15 February & 9 January & 10 February & 12 January \\
\hline
\end{tabular}
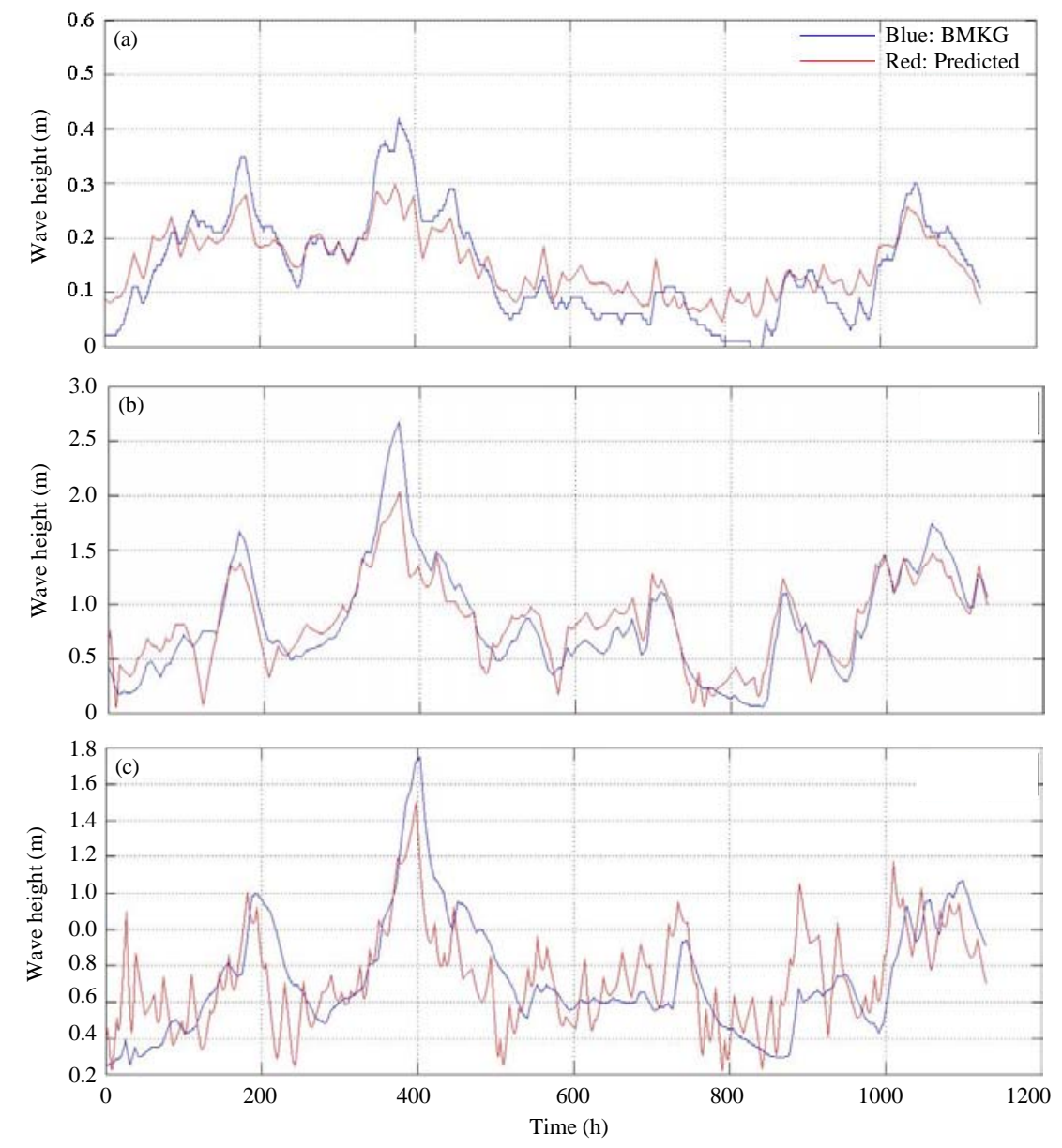

Fig. 6: Wave height point a, b and c prediction: a) hs ( $\mathrm{t}+1) \mathrm{SBY}$; $\mathrm{b})$ hs $(\mathrm{t}+1)$ Laut Java; $\mathrm{c})$ hs $(\mathrm{t}+1)$ Banjar

longitude: $113.908800 \mathrm{E}$ latitude: $4.648136 \mathrm{~S}$ in Java sea (point $\mathrm{B}$ ) a red color and the third to longitude: 114.484300 E latitude: $3.540425 \mathrm{~S}$ in Banjarmasin (point C) magenta color. Off the charts can be seen that who have a height of waves highest namely that is colored red (B).

Table 4-6 represents data wave level in their one point based on the average of per year and altitudes waves million per year. Equal to wind speed, the maximum waves happened in December-February coincide with rainy season.
Prediction: After conducted training and validation, algorithm JST it produces weights which will used to prediction height waves. Figure 6 is a chart prediction height waves each in waters Surabaya (point A), the Java sea (point B) and waters Banjarmasin (point C). Blue is the height of waves of data $\mathrm{BMKG}$ and red is the height of waves the results of a prediction JST based on wind speed, the height of waves now and heights of the waves an hour before. 
Res. J. Applied Sci., 13 (4): 252-257, 2018

Table 3: Wind speed point $\mathrm{C}$ data's

\begin{tabular}{lllllll} 
Variables & 2006 & 2007 & 2008 & 2009 & 2010 & 2011 \\
\hline Average & 5.36 & 4.93 & 5.1 & 4.97 & 3.53 & 4.25 \\
Maxsimum & 11.49 & 13.36 & 10.36 & 11.21 & 10.86 & 12.28 \\
Date & 18 January & 3 January & 8 February & 5 February & 13 January & 12 January \\
\hline
\end{tabular}

Table 4: Wave height point A data

\begin{tabular}{lllllll} 
Variables & 2006 & 2007 & 2008 & 2009 & 2010 \\
\hline Average & 3.9 & 3.8 & 4.04 & 3.72 & 4.07 \\
Maximum & 11.06 & 14.89 & 13.86 & 16.81 & 10.18 \\
Date & 25 January & 29 December & 9 February & 7 February & 31 December \\
\hline
\end{tabular}

Table 5: Wave height point B data

\begin{tabular}{lllllll}
\hline Variables & 2006 & 2007 & 2008 & 2009 & 2010 \\
\hline Average & 1.2 & 0.9 & 0.98 & 0.75 & 0.56 \\
Maximum & 2.51 & 3.42 & 2.48 & 3.04 & 0.94 \\
Date & 27 February & 27 December & 15 February & 9 January & 1.4 \\
\hline
\end{tabular}

Table 6: Wave height point $\mathrm{C}$ data

\begin{tabular}{lllllll}
\hline Variables & 2006 & 2007 & 2008 & 2009 & 2010 \\
\hline Average & 0.73 & 0.68 & 0.72 & 0.64 & 0.51 \\
Maximum & 2.14 & 2.31 & 1.61 & 1.82 & 1.71 \\
Date & 18 January & 3 January & 8 February & 5 February & 1.61 \\
\hline
\end{tabular}

Root Mean Square Error (RMSE) used to assess the relative the predictions. The less RMSE produced, the more both based on a prediction obtained (Paplinska-Swerpel and Paszke, 2006). RMSE prediction in point $\mathrm{A}$ is 0.04 , RMSE prediction in point $\mathrm{B}$ is 0.21 and RMSE prediction in point $\mathrm{C}$ is 0.23 .

\section{CONCLUSION}

This research can be concluded, that algorithm neural network influenced by architecture network and input-output. Algorithm neural network the best there are at a point namely by RMSE 0.04 . In literature review it was mentioned that the less RMSE, the more both based predictions.

\section{REFERENCES}

Agrawal, J.D. and M.C. Deo, 2004. Wave parameter estimation using neural networks. Mar. Struct., 17: 536-550.

Ainsworth, T., N.W.S. Juneau and Alaska, 2011. Significant wave height: A closer look at wave forecasts. Master Thesis, National Oceanic and Atmospheric Administration, United States Department of Commerce that Focuses, Maryland, USA.

Aisjah, A. and S. Arifin, 2011. Maritime weather prediction using fuzzy logic in Java Sea. Proceedings of the 2nd International Conference on Instrumentation Control and Automation (ICA'11), November 15-17, 2011, IEEE, Bandung, Indonesia, ISBN:978-1-4577-1462-7, pp: 205-208.
Aisjah, A., 2012. Design of Information System and Prediction of Maritim Wather for East Java Fisherman. Eko Publisher, Indonesia,.

Akhir, B. and M. Mera, 2011. [Trajectory of sea waves towards the port of baai Island Bengkulu (In Indonesian)]. J. Civil Eng., 7: 47-60.

Anonymous, 2012. [Variability of Sea waves in the Java Sea and the strait of karimata viewed from the perspective of meteorological dynamics]. Faculty of Mathematics and Natural Sciences, University of Indonesia, Depok, Indonesia. (In Indonesian)

Bhattacharya, B., D.L. Shrestha and D.P. Solomatine, 2003. Neural networks in reconstructing missing wave data in sedimentation modelling. Proceedings of the 30th Congress on IAHR Vol. 500, August 24-29, 2003, IAHR, Thessaloniki, Greece, pp: 770-778.

Deo, M.C. and C.S. Naidu, 1998. Real time wave forecasting using neural networks. Ocean Eng., 26: 191-203.

Etemad-Shahidi, A., M.H. Kazeminezhad and S.J. Mousavi, 2009. On the prediction of wave parameters using simplified methods. J. Coastal Res., 1: 505-509.

Gunaydin, K., 2008. The estimation of monthly mean significant wave heights by using artificial neural network and regression methods. Ocean Eng., 35: 1406-1415.

Hakim, J., 2010. [Designing a weather predictor with the fuzzy logic method]. BMKG, Surabaya, Indonesia. (In Indonesian)

Hashim, R., C. Roy, S. Motamedi, S. Shamshirband and D. Petkovic, 2016. Selection of climatic parameters affecting wave height prediction using an enhanced Takagi-Sugeno-based fuzzy methodology. Renewable Sustainable Energy Rev., 60: 246-257. 
Hermawan, A., 2006. [Artificial Neural Network]. Andi Publisher, Yogyakarta, Indonesia, (In Indonesian).

Jain, P. and M.C. Deo, 2008. Artificial intelligence tools to forecast ocean waves in real time. Open Ocean Eng. J., 1: 13-20.

Londhe, S.N., S. Shah, P.R. Dixit, T.B. Nair and P. Sirisha et al., 2016. A coupled numerical and artificial neural network model for improving location specific wave forecast. Appl. Ocean Res., 59: 483-491.

Makarynskyy, O., D. Makarynska, M. Kuhn and W.E. Featherstone, 2004. Predicting sea level variations with artificial neural networks at Hillarys Boat Harbour, Western Australia. Estuarine, Coastal Shelf Sci., 61: 351-360.

Mandal, S., 2010 . Ocean wave prediction using numerical and neural network models. Open Ocean Eng. J., 3: 12-17.
Paplinska-Swerpel, B. and L. Paszke, 2006. Application of neural networks to the prediction of significant wave height at selected locations on the Baltic Sea. Arch. Hydro Eng. Environ. Mech., 53: 183-201.

Paras, M.S., A. Kumar and M. Chandra, 2007. A feature based neural network model for weather forecasting. World Acad. Sci. Eng. Technol., 10: 66-73.

Peres, D.J., C. Iuppa, L. Cavallaro, A. Cancelliere and E. Foti, 2015. Significant wave height record extension by neural networks and reanalysis wind data. Ocean Modell., 94: 128-140.

Srivastava, P.S., 1964. A comparative study of wave forecasting techniques. J. Appl. Meteorol., 3: 206-207.

Sugianto, D.N., 2012. [Model of wind speed data distribution and its utilization in wave forecasting in paciran sea waters, East Java (In Indonesian)]. Mar. Sci. Indonesian J., 15: 143-152.

Triatmodjo, B., 1999. [Beach Engineering]. Beta Publisher, Yogyakarta, Indonesia, (In Indonesian). 